\title{
Numerical analysis of the heat exchanger energy efficiency depending on location from the floor
}

\author{
Magdalena Orłowska, \\ ${ }^{1}$ Technical University of Koszalin, Faculty of Civil Engineering, Environmental and Geodetic \\ Sciences, al. Śniadeckich 2, PL-75-453 Koszalin, Poland
}

\begin{abstract}
The article is a continuation of a series of articles the author 1 on convective heat transfer of heat exchangers working in different building conditions. Location of the window sill, housing enclosing the distance of the radiator from the floor is not without significance, as it turns out. The article presents the results of numerical analysis regarding installation of the heater flat plate in three different distances from the floor.
\end{abstract}

\section{Introduction}

The phenomenon of convection has been known for a long time and widely used technique $[1,2]$. Natural convection heat transfer is associated with the movement of fluid, due to the gravitational field. Fluid with a higher temperature increases its volume, thus reducing its density and rise upwards. Fluid having a temperature lower its density increases, which causes it to fall down [3]. Natural convection is characterized by the extraordinary complexity which hinders detailed and accurate analysis. They are however, very intense fields of studies, both theoretical and experimental or numerical. These studies provide more interesting elements which could be in use. Besides the importance of cognition tend to have the results of increasing the intensity of the convection heat transfer [4].

Heater Installation is usually proposed by the manufacturer. There is always assembly instructions with it connectors attached to the heater determine the distance from the wall, sill or floor. Leaving aesthetic issue aside, it's interesting how parameters such as distance from a building structures has impact on the thermal effect - performance of the heater.

*Corresponding author: magdalena.orlowska@tu.koszalin.pl 
Table 1. Distances proposed by different data sources $[5,6]$.

\begin{tabular}{|c|c|}
\hline Distance & cm \\
\hline From the floor & 10 \\
\hline From the wall & Depending on the type of handles for hanging the radiator \\
\hline From the windowsill & 10 \\
\hline
\end{tabular}

\section{Methodology of Numerical Research}

All simulations were performed using the simulation code Ansys Mechanical APDL / CFD-Flo Preferences for GUI Filtering -Flotran CFD 2D Flotran 141 - Library of Elements Types [7]. The program is based on solving the balance equations of energy, momentum and mass used in CFD- Computational Fluid Dynamic model. The standard version of the simulation code allows you to conduct modeling based on traditional dependence phenomenological equations and additional closures, describing the previously mentioned turbulent momentum and energy streams. The test system was modeled in two-dimensional space. Program calculates after entering the boundary conditions: temperature of the walls of the heat exchanger, room air velocity and gravity [8].

The article presents couple of selected systems with different geometry Fig. 1 and attempted to explain its effects on the intensity of heat exchange (heat transfer coefficient).

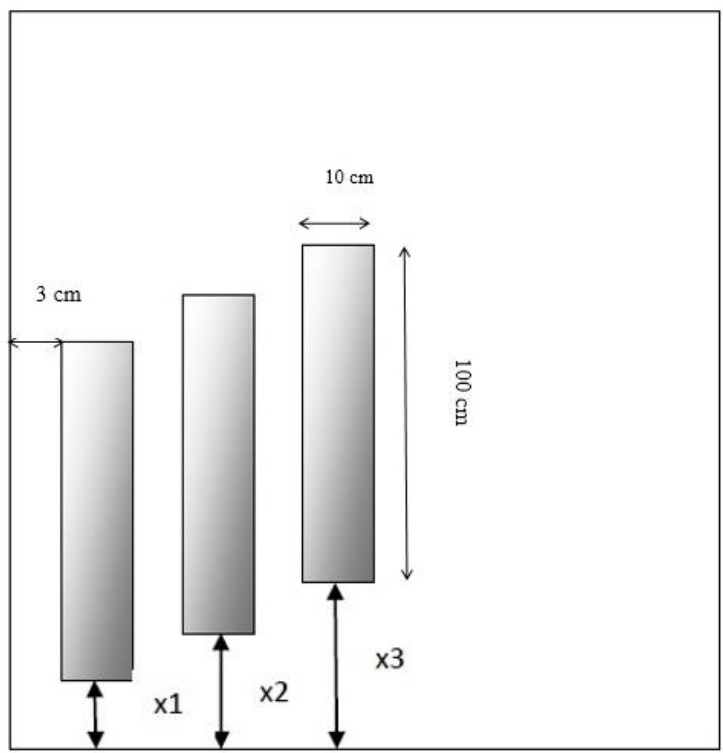

Fig. 1. Scheme subjected to numerical analysis.

\section{Calculation Results}

The study used simulation flat plate heat exchanger with a thickness of $10 \mathrm{~cm}$ and a height of $100 \mathrm{~cm}$ with $3 \mathrm{~cm}$ distance between the wall and the radiator. The heater was tested at three different distances from the floor $\mathrm{x} 1=5 \mathrm{~cm} \times 2=10 \mathrm{~cm}$ and $\mathrm{x} 3=15 \mathrm{~cm}$. The 
dimensions of the room in which the heater was in a width of $3 \mathrm{~m}, 2,5 \mathrm{~m}$ height. The third dimension - length - due to the two-dimensional character of analysis were omitted. Heater wall temperature of $70^{\circ} \mathrm{C}$, the walls of a room of $20^{\circ} \mathrm{C}$.

The results of numerical analysis gave the following graphs: Figures 2, 3, 4, 5:

heat transfer coefficient $\alpha$ along the height of radiator located on different distance from the floor

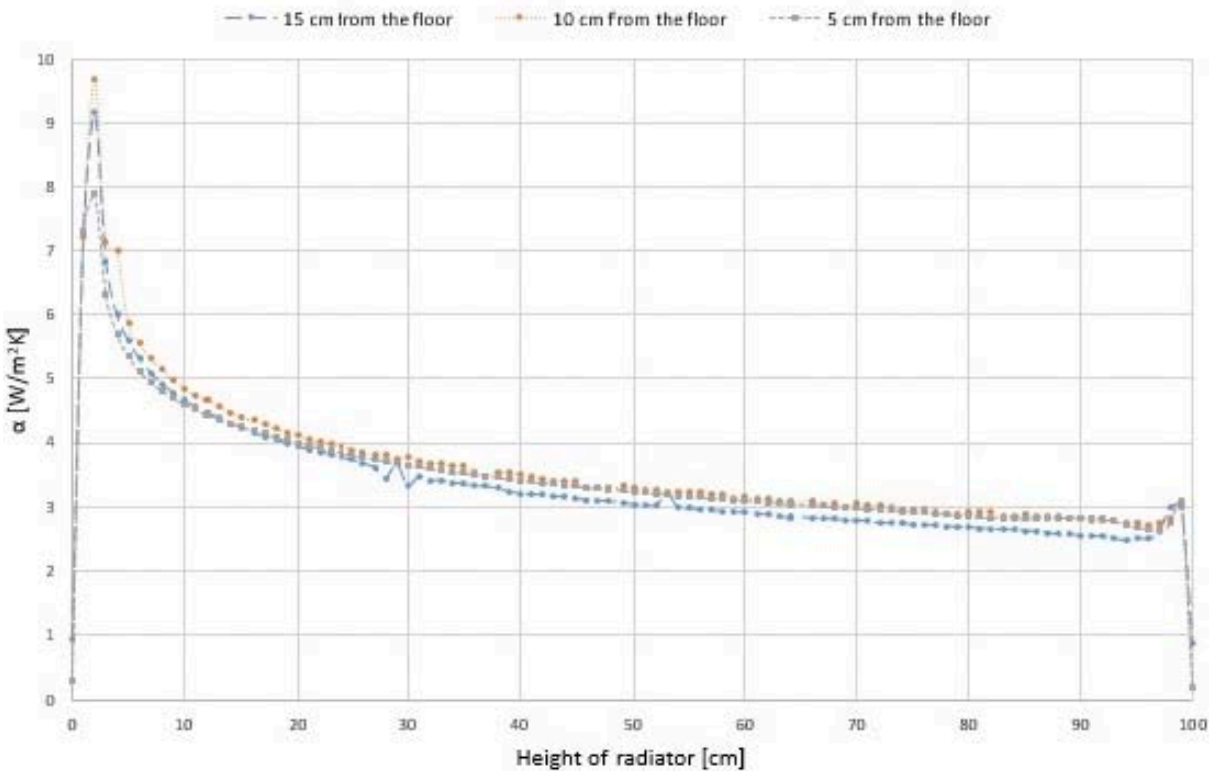

Fig. 2. Heat transfer coefficient $\alpha\left[\mathrm{W} / \mathrm{m}^{2} \mathrm{~K}\right]$ along the height of radiator [cm].

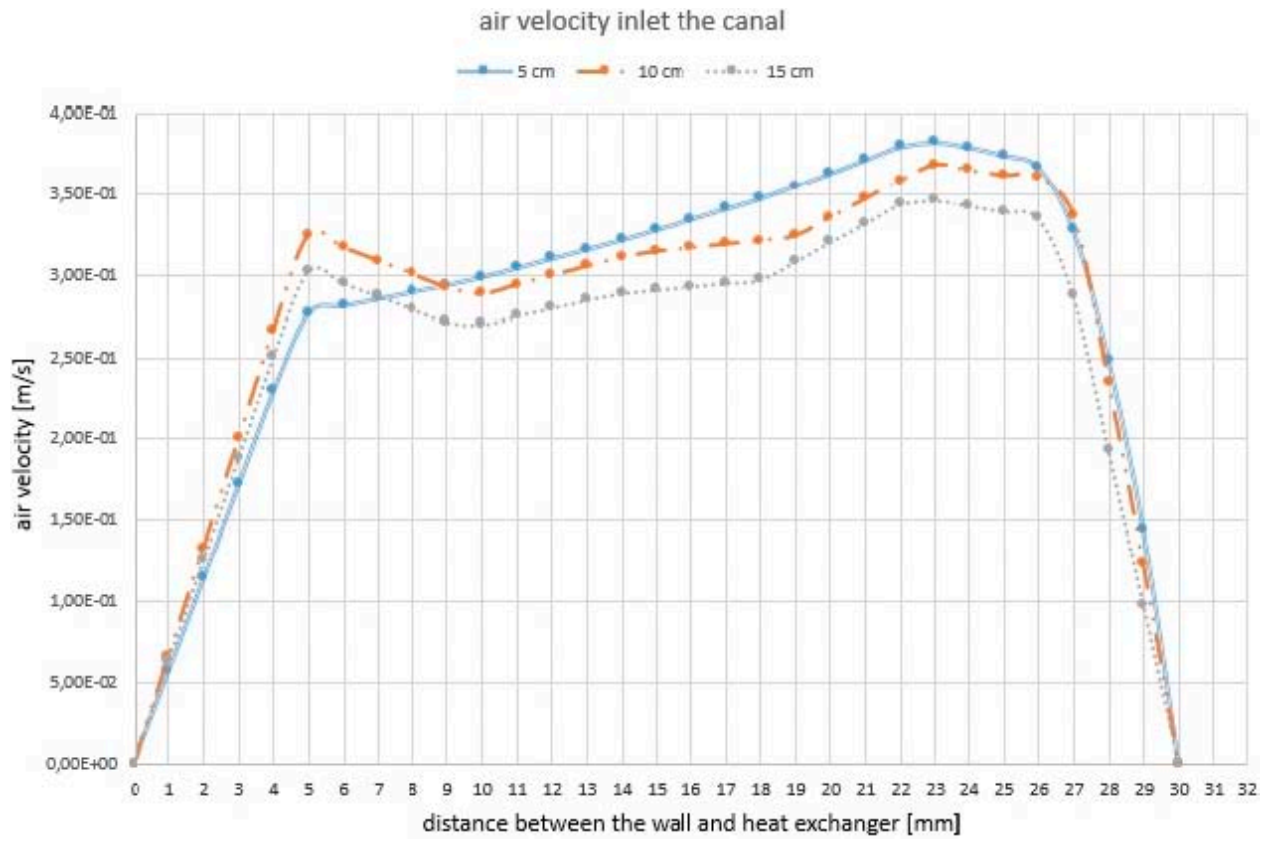

Fig. 3. Air velocity $\mathrm{w}[\mathrm{m} / \mathrm{s}]$ along width at inlet the canal between the wall and heat exchanger $[\mathrm{mm}]$. 
air velocity outlet the canal

$\rightarrow-15 \mathrm{~cm} \rightarrow-10 \mathrm{~cm} \rightarrow-5 \mathrm{~cm}$

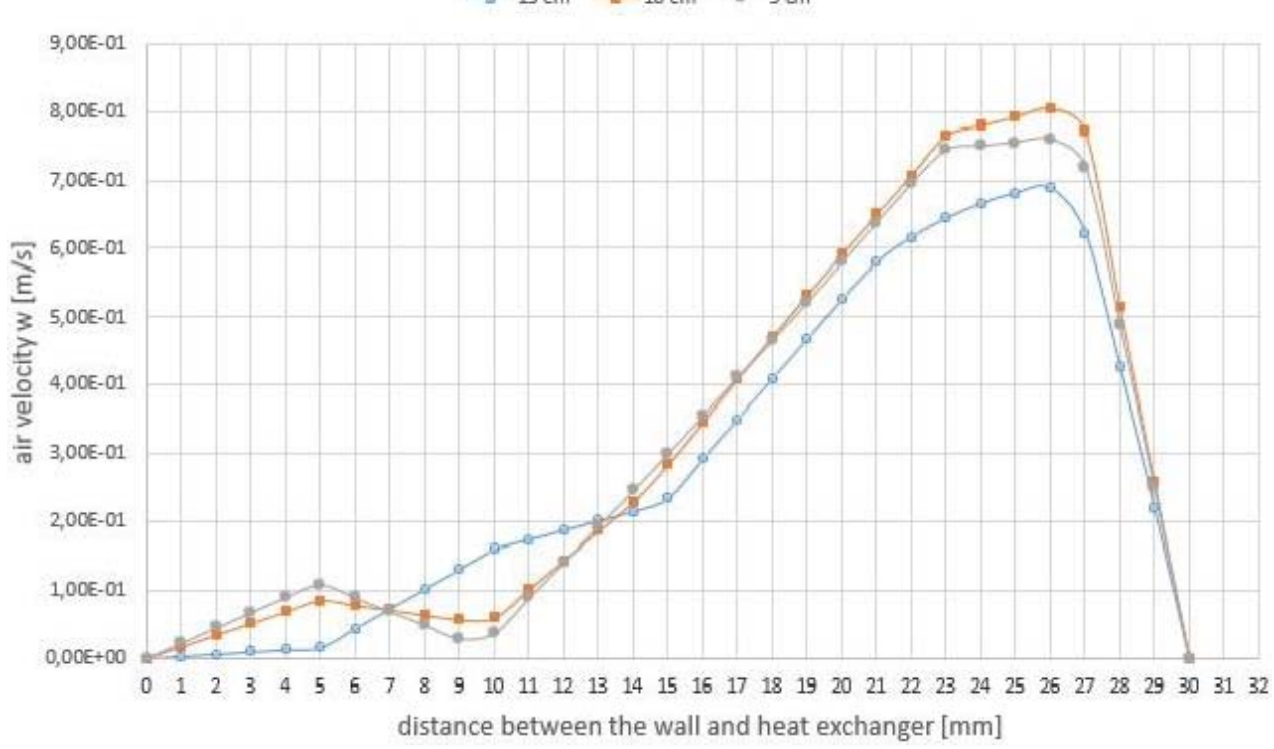

Fig. 4. Air velocity $\mathrm{w}[\mathrm{m} / \mathrm{s}]$ along width at outlet the canal between the wall and heat exchanger $[\mathrm{mm}]$.

air temperature $[\mathrm{K}]$ outlet the canal

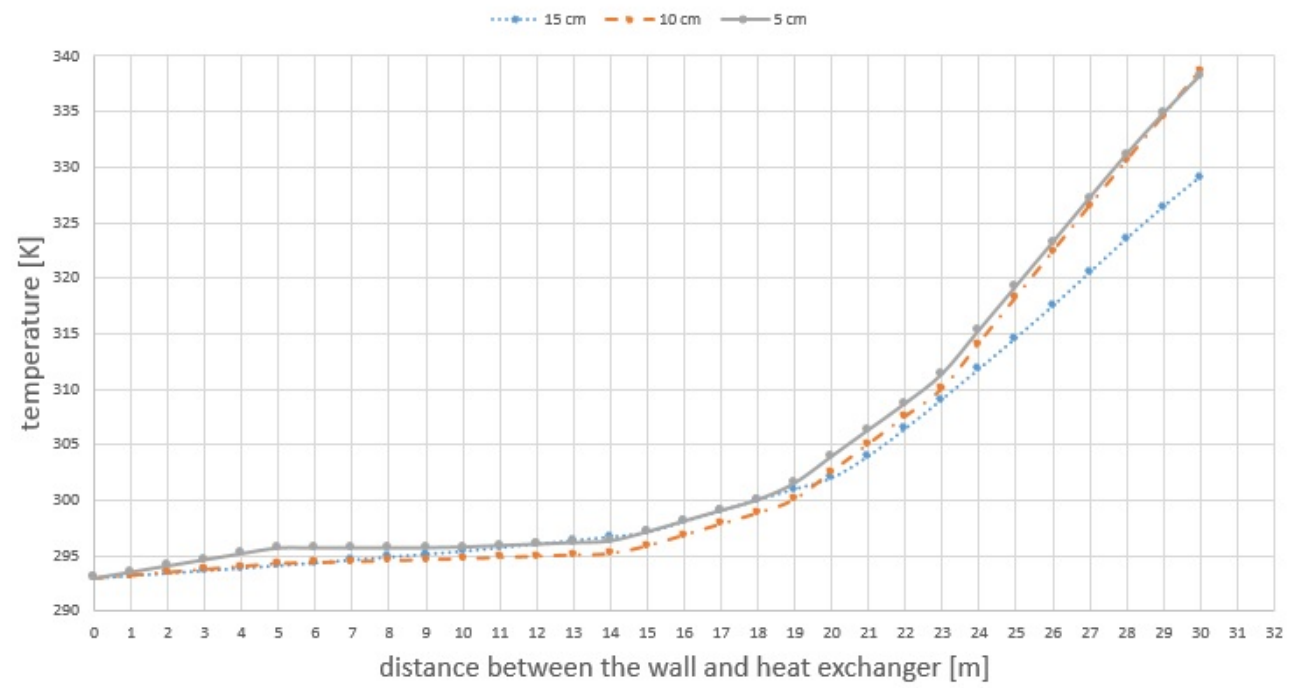

Fig. 5. Air temperature $[\mathrm{K}]$ along width at outlet the canal between the wall and heat exchanger $[\mathrm{mm}]$.

The highest average value of heat transfer coefficient $\alpha=3,58\left[\mathrm{~W} / \mathrm{m}^{2} \mathrm{~K}\right]$ obtained in the case of a heater located at a distance of $10 \mathrm{~cm}$ from the floor, then $5 \mathrm{~cm} \alpha=3,46\left[\mathrm{~W} / \mathrm{m}^{2} \mathrm{~K}\right]$ and $15 \mathrm{~cm} \alpha=3,37\left[\mathrm{~W} / \mathrm{m}^{2} \mathrm{~K}\right]$.

The highest average value of the air velocity in the inlet to the channel obtained in in the case of a heater located at a distance of $5 \mathrm{~cm}$ from the floor $\mathrm{w}=2,77[\mathrm{~m} / \mathrm{s}]$, then $10 \mathrm{~cm}$ $\mathrm{w}=2,74[\mathrm{~m} / \mathrm{s}]$ and the lowest $15 \mathrm{~cm} \mathrm{w}=2,54[\mathrm{~m} / \mathrm{s}]$. 
The highest average value of the air velocity in the outlet to the channel obtained in in the case of a heater located at a distance of $10 \mathrm{~cm}$ from the floor $\mathrm{w}=3,21[\mathrm{~m} / \mathrm{s}]$, then $5 \mathrm{~cm}$ $\mathrm{w}=3,13[\mathrm{~m} / \mathrm{s}]$ and the lowest $15 \mathrm{~cm} \mathrm{w}=2,83[\mathrm{~m} / \mathrm{s}]$.

The highest average value of the air temperature at the outlet of the $\mathrm{T}=304,68 \mathrm{~K}$ was prepared in a $5 \mathrm{~cm}$ distance between the floor and the radiator, the average value temperature in the system from a distance of $10 \mathrm{~cm} \mathrm{~T}=303,7 \mathrm{~K}$ and lowest temperature $\mathrm{T}=302,6 \mathrm{~K}$ system of $15 \mathrm{~cm}$ distance.

If the heater is too low from the floor it causes the speed of the incoming airflow to the inlet of the channel between the wall and the radiator is large but it is reduced later. System with $15 \mathrm{~cm}$ distance performed the worst in terms of received speed and air temperature and the ratio of the heat transfer $\alpha$.

\section{Conlusions}

Finally the best system in terms of heat exchange results are achieved with a heater positioned $10 \mathrm{~cm}$ from the floor. It allows air to circulate freely and is considered optimal from a distance. The results of the numerical analysis can be a valuable source of data. We've received important informations on the flat radiators. This informations can be useful for companies involved in installation of radiators or repairing the apartment and struggling with the proper placement of heat exchangers.

\section{References}

1. M. Orłowska, M. Czapp, Rocznik Ochrony Środowiska XIV (2012)

2. S. Czapp, M. Czapp, M. Orłowska, Numerical and experimental investigation of thermal convection near electric devices with vertical channels, 2016 International Conference on Information and Digital Technologies (IDT), Rzeszow, 2016, pp. 54-58 (2016)

3. M. Szpakowska, Badanie wpływu warunków brzegowych na intensyfikację konwekcyjnej wymiany ciepła od płyty pionowej w przestrzeni częściowo ograniczonej, PhD thesis (2010)

4. M. Czapp, H. Charun, J. Baran, Chłodnictwo 6 (1980).

5. www.instalreporter.pl/ogolna/montaz-grzejnikow-zaleznie-od-ich-rodzaju-na-roznychscianach/

6. www.regulus.com.pl/faq/jaka-jest-prawidlowa-odleglosc-grzejnika-od-parapetu-ipodlogi

7. Ansys, User Instruction

8. M. Orłowska, Numerical analysis at a plate heat exchanger with covers- selected variations, Heat Transfer and Heat Exchangers - Heat Transfer and Renewable Sources of Energy HTRSE 2016, pp. 225-228 (2016) 